\title{
EL FAMILY OFFICE COMO ÓRGANO DE CONTROL DE FINANCIAMIENTO DE LAS EMPRESAS FAMILIARES
}

\author{
Sandra Violeta Echaiz Moreno ${ }^{1}$
}

\section{RESUMEN}

El presente artículo está orientado a aquellas familias que habiendo constituido empresas familiares cuentan con capitales millonarios y a quienes se les sugiere, mediante un Consejo de Familia, constituir Family Office con la finalidad de tener un mejor control del financiamiento de sus empresas y llegar a distinguir con claridad cuál es el patrimonio de la empresa familiar y cuando es el patrimonio familiar. Está institución está orientada a empresas familiares de capitales superiores a los 100 millones de dólares y sirve como un mecanismo de inversión de grandes proyectos en donde se procurará preservar el patrimonio económico en aras de proteger a las futuras generaciones.

\section{ABSTRAC}

This paper is intended for families who, having set up family companies, have millions of dollars and who have been suggested, through a Family Council, to establish a Family Office in order to have a better control over the financing of their companies and to distinguish eith clarity what is the family business' assets and what is the family's assets. This institution aims at family businesses with capital exceeding 100 million US dollars and serves as an investment mechanism for large projects where efforts will be made to preserve the financial assets in order to protect future generations.

\section{PALABRAS CLAVES}

Family Office. Multi Family Office. Patrimonio Empresarial. Patrimonio Familiar. Empresas Familiares. Control de Financiamiento. Consejo de Familia. Fondos de Inversión.

\section{KEYWORDS}

Family Office. Multi Family Office. Company Assets. Family Assets. Family Companies. Control of Funding. Family Council. Investment Funds.

Socia de ECHAIZ ABOGADOS. Abogada summa cum laude por la Pontificia Universidad Católica del Perú, con estudios concluidos en la Maestría en Derecho de Empresa de la Universidad Peruana de Ciencias Aplicadas. Catedrática de la Universidad Peruana de Ciencias Aplicadas y de la Universidad San Ignacio de Loyola. Consultora en Gobierno Corporativo de pequeñas y medianas empresas familiares por la Cámara de Comercio de Lima. Investigadora académica del Instituto Argentino de la Empresa Familiar. Autora de "Derecho y empresas familiares. El protocolo familiar en las MYPES familiares peruanas", coautora de dos obras colectivas internacionales y de 20 artículos en materia empresarial. (E-mail: sandra@echaiz.com). 


\section{INTRODUCCIÓN}

Las empresas familiares son organizaciones con una mística especial, al estar conformadas por miembros familiares que participan activamente en la propiedad de la empresa, y de manera complementaria, en la administración y gestión de la misma. El hecho que la familia participe y forje la empresa, trae una serie de ventajas para la misma, siendo una de las más importantes, el compromiso de los miembros familiares en hacer prosperar una empresa que dará resultados positivos y redituará hacia su familia, y a las siguientes generaciones; lo cual va sumamente ligado a la intensión permanente de la familia de aportar dinero (como capital, préstamo u otras modalidades) para sacar adelante la empresa.

Sin embargo, es una característica (también problemática por resolver) de las empresas familiares, que exista una confusión del patrimonio empresarial y familiar, así como el permanente autofinanciamiento que realizan los miembros familiares, para realizar los proyectos empresariales de manera más expeditiva; lo cual finalmente, termina generando una serie de conflictos entre los miembros familiares, que se revierten en consecuencias negativas para la empresa familiar (desde simples discusiones por temas financieros hasta tomar decisiones radicales como la liquidación o cierre de la empresa familiar, o la venta de la mis$\mathrm{ma})$.

Sucede que cuando las empresas familiares son pequeñas y hasta medianas, es aún posible manejar estos problemas de carácter financiero que se pueden presentar dentro de la empresa; sin embargo, cuando la empresa familiar crece y presenta variantes como: a) convivencia de varias generaciones en la propiedad y administración de la empresa, b) patrimonio alto de la empresa familiar, c) necesidad de financiamiento para nuevas inversiones de negocio de la familia, y d) dificultad para administrar adecuadamente patrimonios altos de empresas familiares; es necesaria la intervención de un órgano especial que se encargue de manejar estos temas.

Por lo tanto, siendo que las empresas familiares constituyen la mayor parte del empresariado peruano y representan a su vez, la "columna vertebral de la economía del país", es importante adoptar medidas dentro de las mismas que permitan la continuidad de las empresas familiares y supervivencia en manos de las propias generaciones familiares. En este caso en específico, desarrollaremos la oficina familiar o family office como órgano clave de gobierno fa- miliar que permita el manejo y control de financiamiento dentro de las empresas familiares grandes.

\section{Definición}

La oficina familiar o más conocida como family office es un ente que depende normalmente y ha sido constituido por el Consejo de Familia ${ }^{2}$ con el fin de profesionalizar la gestión del patrimonio de la familia empresaria cuando éste ha alcanzado niveles de crecimiento altos, y requiere una administración especial, que le permita un desarrollo y supervivencia que se perpetúe con el paso de las generaciones y siempre en manos de la familia empresaria. Son familias que buscan asesoramiento específico de índole financiero, bancario, tributario y aspectos similares.

John Ward ha definido el family office como la "organización profesional dedicada a la gestión del patrimonio familiar y los asuntos familiares que está hoy en día redefiniendo el arte de la gestión patrimonial efectiva en familias empresariales que poseen gran visión a largo plazo y un fuerte sentido de propósito y valor de sus fortunas" 3 . Sin embargo, debemos comprender que este órgano es un ente dinámico y cambiante que se adapta a los requerimientos y las necesidades de cada familia empresaria, constituyéndose en algu-

2 El Consejo de Familia es el órgano decisorio y deliberativo de la empresa familiar que sirve de vínculo entre la familia empresaria y los órganos de gobierno de la empresa familiar, y que adopta decisiones importantes para el destino de ésta. Las funciones del consejo de familia no se deben confundir con las del directorio, considerando que ambos se encargan del plan estratégico del negocio, sólo que el primero desde el punto de vista familiar, y el segundo desde el punto de vista empresarial. Cfr. Echaiz Moreno, Sandra Violeta. Derecho y empresas familiares. Lima (2014): Thomson Reuters, pp. 219-221.

3 Cfr. Cazorla, Julio. "Fundamentos de un Family Office”. Newsletter de Empresa Familiar. Barcelona, número 58, pp. 1. 
nos casos como una empresa independiente y en otros casos no, sino simplemente como un órgano de la empresa familiar, no existiendo reglas claras o exigencias básicas para su constitución o formación, como nos refiere un estudio del Diario Expansión ${ }^{4}$.

Antonio Gallardo, presidente de Landon Grupo Corporativo, el family office de la familia Gallardo, manifiesta ${ }^{5}$ que la motivación para crear este ente en su familia fue el ingreso de socios externos a su empresa, que obligaba la separación de negocio y patrimonio. Asimismo señala que debido a los costes que implica la constitución de un family office, sólo vale la pena en empresas familiares con patrimonios realmente altos; inclusive en Estados Unidos, se aconseja a patrimonios mayores a $100 \mathrm{mi}$ llones de dólares. Si es menor, sería mejor acudir a un Multi Family Office, que son dependencias que se han creado en bancos privados o como entes independientes, que se encargan de gestionar el patrimonio de "varias" familias empresarias.

Desde nuestra perspectiva, este órgano podría ser sumamente útil para las empresas familiares peruanas, siempre que lo adaptemos a nuestra realidad, tomando en consideración el esquema original de Europa o Estados Unidos que usan este órgano como un mecanismo de inversión en grandes proyectos, cuando la fami- lia empresaria tiene un patrimonio elevado que merezca la constitución del family office.

Así, como señaló el Diario Gestión, citando cifras de The Boston Consulting Group, "hay en el mundo más de 14,600 familias con, al menos, US\$ 100 millones en activos, un $42 \%$ más que en 2008; por lo que surge la necesidad que creen sus propias oficinas para administrar sus inversiones y vida cotidiana"6. En nuestro caso sería muy útil como un mecanismo que ayude a nuestras empresas familiares peruanas con patrimonios altos, a distinguir la caja de la empresa familiar de la caja de la familia empresaria (problema que siempre les aqueja) y les ayude a gestionar mejor su patrimonio e inversiones a favor de la familia y la empresa.

Aterrizando a la realidad peruana, se estima que existen 100 mil familias que cuentan con depósitos por más de $\mathrm{S} /$ 9,5 millones; alcanzando en conjunto S/ 1,700 millones ${ }^{7}$. Por tanto, estas familias acaudaladas siendo que la gran mayoría de ellas han hecho empresas, requieren de órganos especiales que se encarguen de gestionar su patrimonio y proteger sus inversiones, y es allí, cuando surge la necesidad de establecer el family office en las empresas familiares peruanas.

\section{COMPOSICIÓN}

Dada la especialidad de los temas que se ven en el family office, siendo labores complementarias a las empresas familiares pero no relacionadas al giro del negocio, como son temas de tributos, inversiones, seguros, etc., requiere de personal capacitado y profesional que asuma los cargos de conformación de este órgano. Normalmente, sabemos que dentro de una empresa familiar no siempre se encuentra a las personas más preparadas y capacitadas para temas específicos, por lo que ameritaría el ingreso de externos que puedan desempeñar una mejor labor, y quizás se permita la inclusión de miembros de la familia a modo de supervisión. Esto será el resultado del proceso de profesionalización que haya desarrollado cada empresa familiar y que incluya a profesionales para los cargos, que sean o no de la familia, dependiendo de los méritos que hayan alcanzado a nivel académico y profesional.

Sin embargo, vemos casos como el del Grupo Xriser, family office de los hermanos Serratosa Luján de España, fundada en el 2007 y que se encuentra presidida por Pablo Serratosa, uno de los hermanos. Este family office ha tenido resultados exitosos en sus tres líneas de inversión: en capital, en empresas y en el sector inmobiliario, debido a que quien lo preside es una persona muy profesional y capacitada para el cargo, y ha adoptado muy buenas decisiones en estas tres líneas de inversión, que siguen beneficiando y ge-

Cfr. Diario Expansión. "Tras la pista de los family office”. 25 de mayo de 2008.

5 Cfr. Cátedra de la Empresa Familiar. "El Family Office es la casa común de la familia. Entrevista a Antonio Gallardo". Newsletter de la Empresa familiar. Barcelona, número 58, pp. 1

6 Cfr. Diario Gestión. "Dentro de la family office de un multimillonario”. 21 de abril de 2015.

7 Cfr. Diario Gestión. “Los family offices pueden salvarlo de errores y multiplicar su legado". 28 de noviembre de 2015. 
nerando incrementos en el patrimonio de la familia Serratosa Luján. ${ }^{8}$

Es importante que temas como la conformación del family office, su período de duración, los requisitos para pertenecer al cargo, las funciones a desarrollar y la remuneración a percibir (ya sean externos o no a la familia, se decida o no pagarles, o inclusive así se contrate a un órgano externo para estas funciones) sean debidamente especificados en el protocolo familiar de la empresa, para que así todo quede claro para la adecuada organización de la familia empresaria.

\section{FUNCIONES}

El family office buscará preservar el patrimonio familiar en manos de la familia empresaria a mediano y largo plazo, por lo que las funciones que a continuación detallaremos, recogidas adecuadamente por Cazorla9, irán en relación a este propósito:

- Prestación de servicios de planificación patrimonial individual y fiscal, consolidación contable, servicios bancarios, administración financiera, seguros.

- Gestión de negocio y patrimonio a través de la gestión inmobiliaria, inversión financiera, el private equity, otras inversiones patrimoniales, etc.

Asimismo, Cazorla nos señala que, en relación a las funcio- nes antes señaladas y de manera gradual, el family office puede cumplir cuatro roles:

- Rol de integrador: coordinación centralizada de servicios financieros o personales de los miembros de la familia.

- Rol de educador y mentor: formación y training financiero de los miembros de la familia.

- Rol de coordinador de transiciones: previsión y preparación para los inevitables cambios que se producen en la vida de la empresa.

- Rol de prevención de riesgos: protección de los activos y patrimonio familiar.

Inclusive, sabemos que las grandes familias suelen realizar labores de filantropía, por lo que el family office no sólo serviría para realizar el aporte benéfico, sino para verificar que el mismo se esté empleando para los fines previstos.

\section{CONCLUSIONES}

La oficina o family office como órgano de gobierno que hemos planteado para la familia empresaria, constituye una propuesta de Gobierno Corporativo empresarial para una empresa familiar, por lo que no está regulada en las leyes y sería de origen contractual a través del protocolo familiar y por decisión de los socios para su conformación. En ese senti- do, es una práctica voluntaria, pero aconsejable para las empresas familiares.

Ahora bien, se podría señalar que en los últimos años, los Fondos de Inversión han sido entidades que se han encargado de gestionar y asesorar a empresas en relación a sus inversiones, estando dentro de ese ámbito, las empresas familiares; pero atendiendo a la necesidad de asesoría en cuanto a temas financieros de empresas familiares, que hemos expuesto a través de este artículo, podría reorientarse a los Fondos de Inversión, a efectos de promover la especialización y constitución de algunos que se encarguen solamente de la gestión de patrimonios de familias acaudaladas.

Por lo tanto, habiendo analizado la importancia del family office dentro de las empresas familiares peruanas, éstas deberían considerar y analizar la inclusión de este órgano (atendiendo a la realidad y crecimiento de la misma) y de tomar la decisión de incorporarlo, insertar a los mejores profesionales dentro de este órgano, ya que se va encargar de gestionar el patrimonio (y en conclusión, el futuro económico) de la empresa familiar. De no poder contar con este órgano dentro de la empresa familiar, queda la opción para las empresas familiares de recurrir a un Multy Family Office, a efectos que se encargue de la gestión de su patrimonio familiar.

\footnotetext{
8 Cfr. Diario Expansión. “Los Serratosa invierten 21 millones en un edificio estrella en Valencia”. 21 de julio de 2011, pp. 13.

9 Cfr. Cazorla, Julio. Op. Cit.
} 